\title{
LA ÚLTIMA BATALLA DEL EMPERADOR DEL MUNDO
}

\section{THE LAST BATTLE OF THE WORLD'S EMPEROR}

\author{
Miriam Tejero López \\ Universidad de Granada.
}

\section{RESUMEN}

$\mathrm{Al}$ abordar el estudio de la imagen literaria de Carlos V, son cuantiosos los relatos de orden heroico que exaltan su grandeza. Sin embargo, el escritor argentino Mujica Láinez, en Un novelista en el Museo del Prado, refleja no sólo eso, sino también su propio temperamento melancólico a través del Carlos $V$ en la batalla de Mühlberg de Tiziano, la pintura más emblemática del emperador. En el cuento final de su última novela, el César pretende librar la batalla más importante de su vida, aquella para la que se preparó en el remoto monasterio extremeño de Yuste. Se enfrenta a un enemigo difícil, pero no imposible de vencer. Un breve recorrido, en busca de la gloria eterna, en el que la melancolía es el elemento conductor para que pintura y poesía se fundan, dando lugar a un retrato muy acertado del que fue emperador del mundo en el siglo XVI.

Palabras clave: Carlos V, Gloria, Melancolía, Mujica Láinez, Tiziano.

\section{ABSTRACT}

When approaching the study of the literary image of Carlos V, the stories of heroic order that exalt his greatness are numerous. However, the Argentine writer Mujica Láinez, in Un novelista en el Museo del Prado, reflects not only that, but also his own melancholic temperament through Titian's Charles V in the Battle of Mühlberg, the emperor's most emblematic painting. In the final tale of his latest novel, César intends to fight the most important battle of his life, the one for which he prepared in the remote Extremadura monastery of Yuste. He faces a difficult enemy, but not impossible to defeat. A brief journey in search of eternal glory, in which melancholy is the guiding element so that painting and poetry are founded, giving rise to a very wise portrait of the one who was emperor of the world in the 16th century.

Key words: Charles V, Glory, Melancholy, Mujica Láinez, Titian. 
Un novelista en el Museo del Prado es la última novela del escritor argentino Manuel Mujica Láinez, también conocido como Manucho, publicada en 1984. Culmina así esa línea de novelas históricas que había iniciado con Boomarzo, El Unicornio, El laberinto y El Escarabajo. La novela, cuyo referente más directo se halla en Tres horas en el Museo del Prado de Eugenio D’Ors (1923), transcurre en los pasillos de la reconocida pinacoteca. Siguiendo el precepto modernista de fusionar las distintas disciplinas artísticas, se compone de doce cuentos en los que los protagonistas son los mismos personajes de las obras de arte que custodia el museo. Al caer la noche, estos cobran vida y de su transitar nocturno es espectador el novelista. Los doce cuentos tienen un denominador común, que aflora a través de la prosa con cualidades plásticas que utiliza el autor, esa reflexión en torno al tiempo, en su caso infinito, que permite vislumbrar el carácter melancólico de todas las criaturas que los protagonizan (Blanco Fresnadillo, 2018).

Como ya han señalado los estudiosos de la producción de Mujica Láinez, el tiempo, fue uno de los temas dominantes en su narrativa (Blanco Fresnadillo, 2013:32). El concepto de tiempo engarza directamente con Saturno, planeta y dios de la melancolía. Igualmente, Saturno aglutina esa lucha de opuestos que tanto nos interesa: locura- genialidad, muertevida (Klibansky et al., 1991).

Atendiendo a esta serie de conceptos, nosotros nos centraremos en el último cuento, “El emperador". En este caso será el Carlos V a caballo, que pintó Tiziano en 1548 en Mühlberg, el protagonista. El novelista nos describe como el César sale de su marco y pasea por el museo hasta detenerse ante la pintura de El Triunfo de la muerte (1562) de Brueghel el Viejo. Bajo los preceptos horacianos del ut pictura poesis (Agudelo, 2011), Mujica Láinez nos describe poéticamente todo el horror macabro que acontece en la obra del pintor holandés, en la que ningún ser, independientemente del poder terrenal que posea, escapa a la guadaña de la muerte. Tras una dilatada contemplación, el emperador se sumerge en esta truculenta vorágine para enfrentarse a su último enemigo. Sin embargo, la batalla no tiene lugar y abatido regresa al marco que le da cobijo en el edificio de Villanueva. Este cuento es el broche final a ese canto a la melancolía que, debajo de todo el entramado iconográfico trazado por el escritor argentino, subyace en toda la novela. Así pues, terminar con una obra del gran maestro de la pintura veneciana, Tiziano, en la que el representado es el hombre más poderoso del s. XVI y al que también le atormenta el tiempo, no es casualidad.

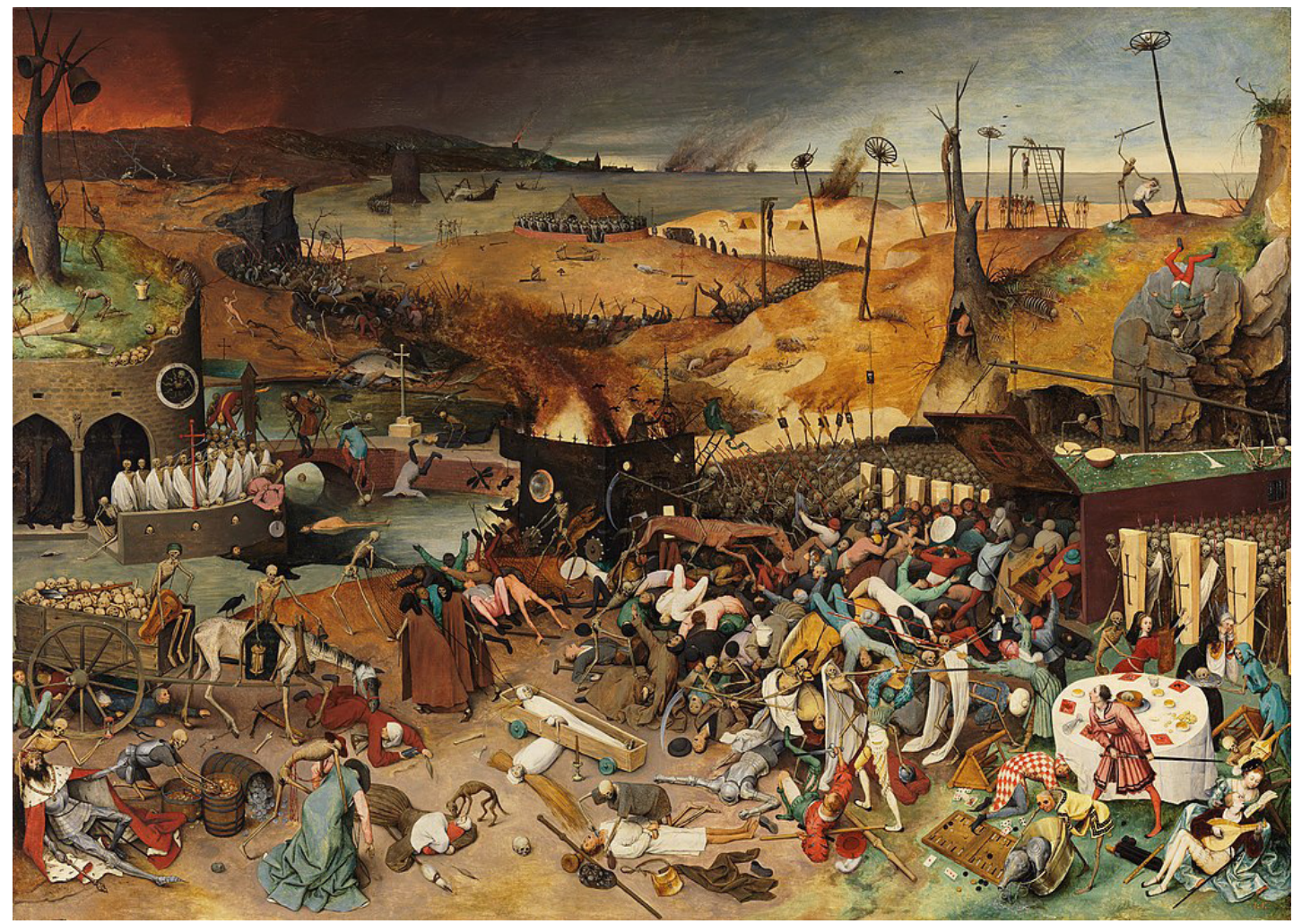

Figura 1.Pieter Bruegel El Viejo. El triunfo de la muerte. 1562-1563. Museo del Prado. 


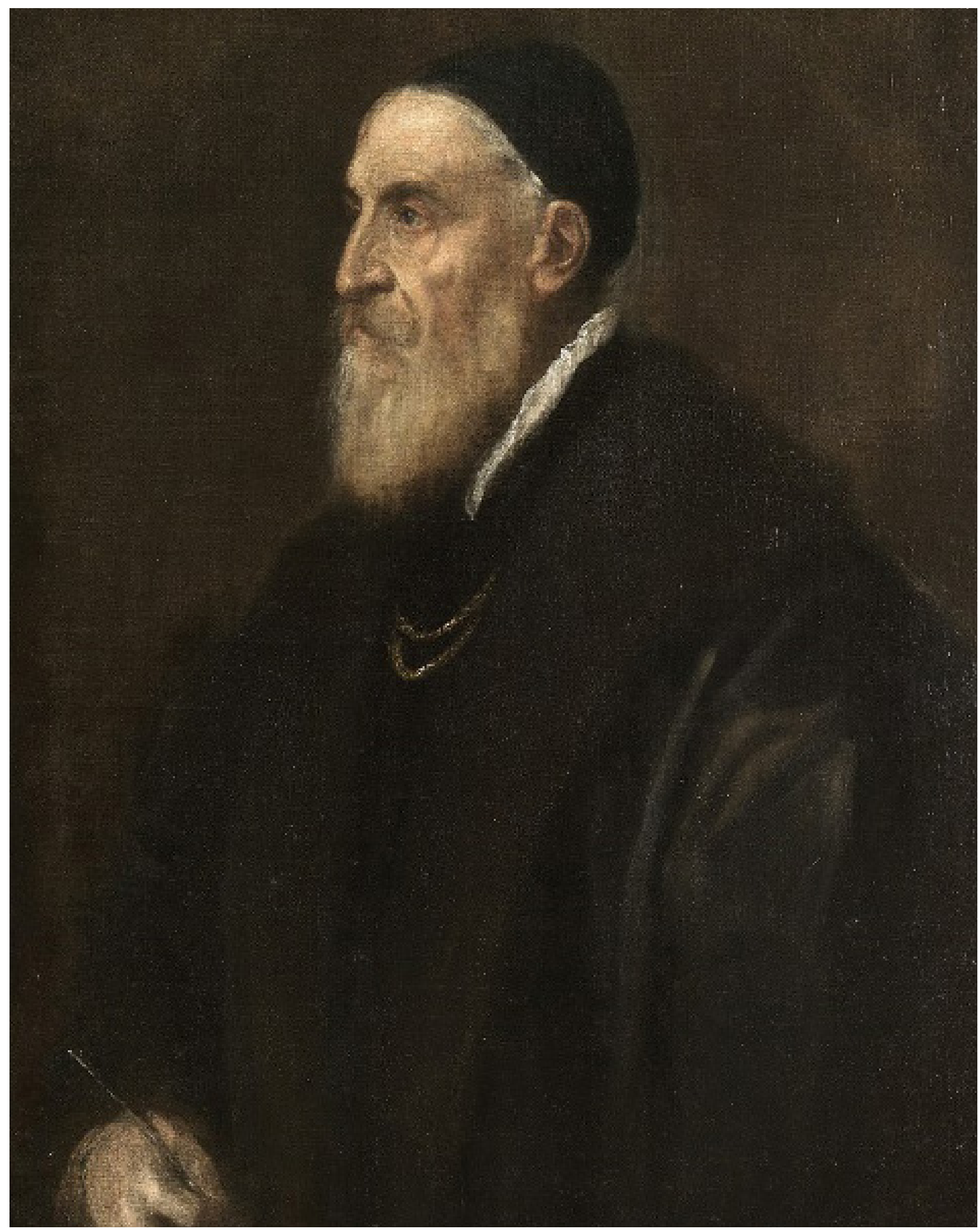

Figura 2. Tiziano. Autorretrato. 1562. Museo del Prado.

En Tres horas en el Museo del Prado, referente para Mujica Láinez, Eugenio D’Ors, refiriéndose al autorretrato del pintor afirmaba "O que mire en el espejo de su Autorretrato sus ojos orgullosos o la melancolía de su barba de nonagenario” (D’Ors, 1923/1993:140) aludiendo, de esta forma, a la teoría aristotélica de que la melancolía se cierne sobre los artistas (Klibansky et al., 1991:54-56). De hecho, Carlos V eligió a Tiziano como retratista porque el veneciano, sin obviar las referencias a la tradición iconografía, era capaz de crear retratos naturalistas que reflejaban, no solo la dignidad del representado, sino también su vida interior (Mancini, 2000). Es por esto que el emperador en los años 30, tras el retrato que le realiza Parmigianino, cargado de referencias alegóricas, prefiriese la aparente simplicidad, más efectiva a sus propósitos, con la que era captado bajo la mirada de Tiziano. El Carlos V en Mühlberg, en el que se inspira Mujica Láinez, entra en relación con otro retrato que, paralelamente a este, realizó el pintor, nos referimos al Carlos V sentado, actualmente en Múnich. En él, Tiziano cambia la representación heroica militar del César, por otra mucho más humana, en la que el peso de los 
años y el sufrimiento padecido por sus constantes ataques de gota, nos muestra a un Carlos V más cercano a la realidad de cualquier terrestre. Ambos cuadros forman parte de ese discurso imperial, que quiere reivindicar su condición como hombre de Armas y Letras (Mancini, 2000). Lo que realmente nos atañe recalcar es que en ambas pinturas, el que casi fue amo del mundo, aparece en completo aislamiento. Soledad de la que también hace acopio Mujica Láinez en su cuento: "Él seguía, impasible en su augusta soledad, en medio de una doble fila de encendidas, de titilantes piedras preciosas. Sobre su peto, cascabeleaba el dije del Toisón” (Mujica Láinez, 1984:144). La tristeza en la mirada es otro de los rasgos perceptibles en ambas obras. ¿Pero qué podía anhelar aquel que todo lo dominaba?

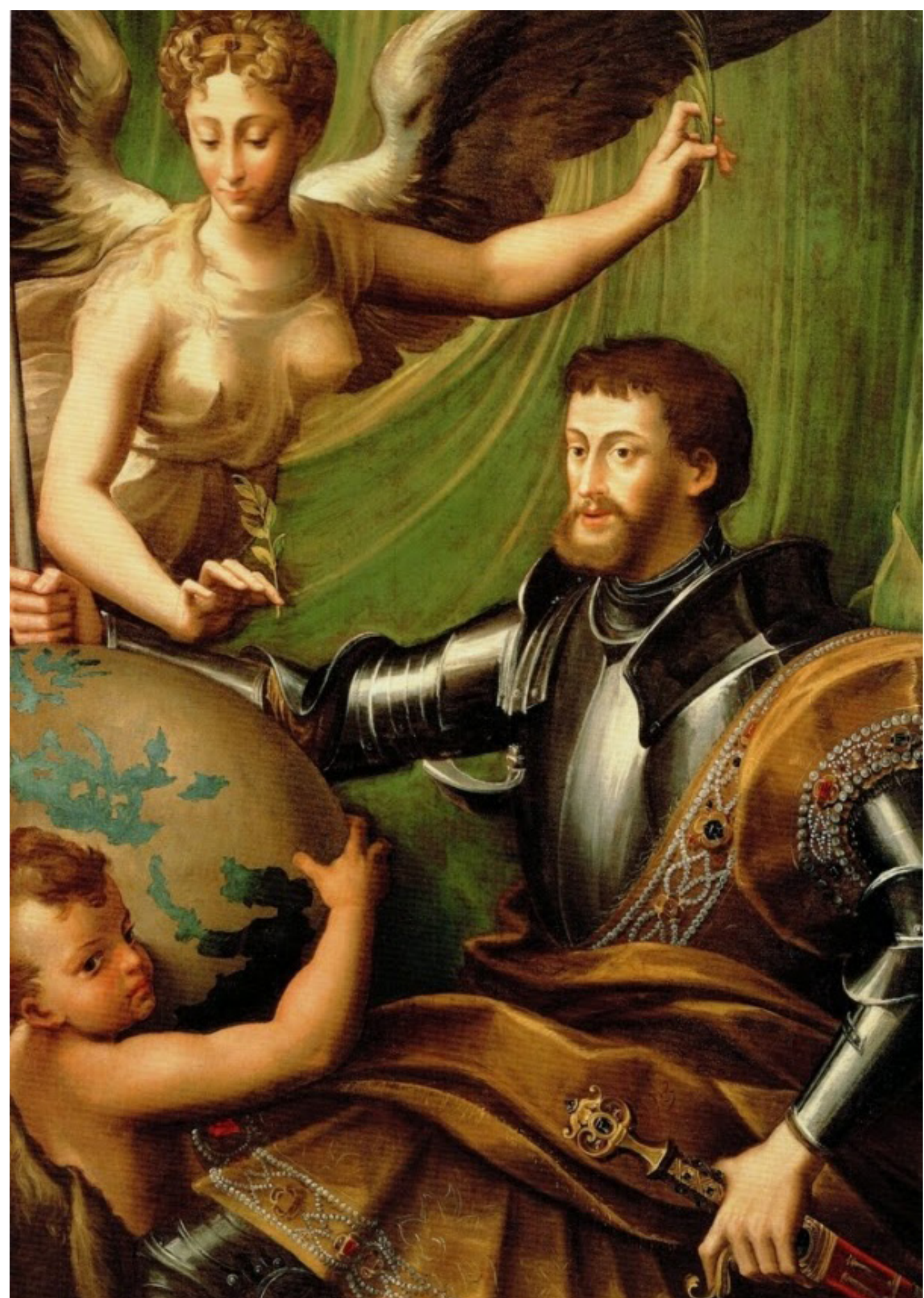

Figura 3. Parmigianino. Carlos V recibiendo El Mundo. 1529. Rosenberg \& Stiebel. 


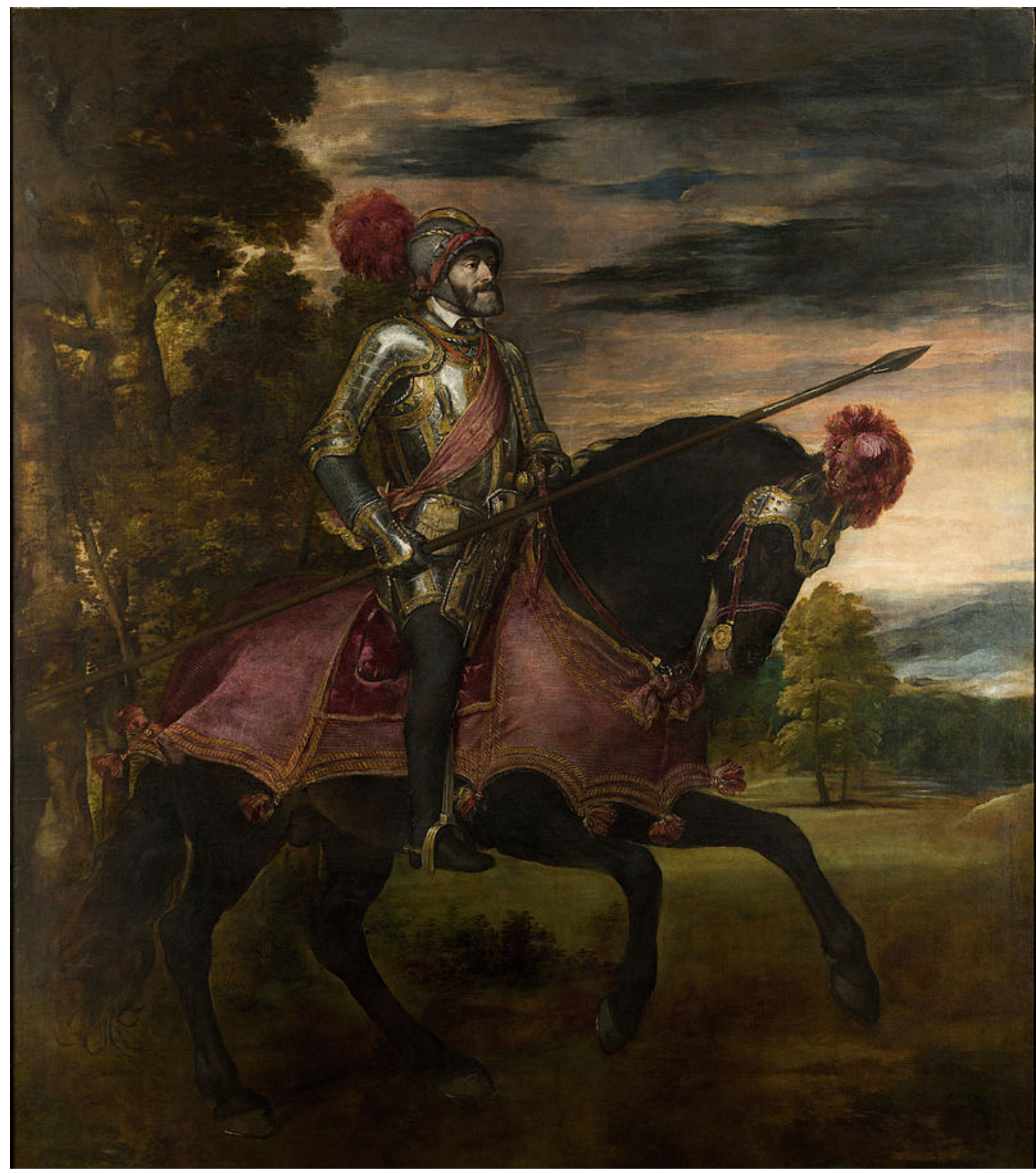

Figura 4. Tiziano. Carlos V en la Batalla de Mühlberg. 1548. Museo del Prado.

Lo cierto es que Carlos V era regente de un imperio inabarcable, que obtuvo por una serie de casualidades dinásticas, y toda su vida estuvo dedicada a lograr dos objetivos que guiaban y justificaban su política imperial: restablecer la unidad en la fe cristiana, quebrada por la aparición de la reforma luterana, y poner fin al avance turco (Pérez, 2000:243). Ninguno de estos objetivos fue alcanzado. Mujica Láinez (1984), también se refiere a su imperio colonial: "En el vasto Mundo conocido, sus tropas estremecían la tierra. Hasta incalculables distancias, en lugares de ídolos y selvas, jamás hollados por la gente de Europa [...]” (p. 151). Tampoco allí logró detener los abusos cometidos contra los indios a través de la aplicación efectiva de las Leyes Nuevas de 1542 (García Añoveros, 2000:77-78), objetivo imposible debido a la distancia abismal e incontrolable que separaba sus territorios a ambos lados del océano, así como a los particulares y distintos intereses de las personalidades que dieron forma a la sociedad virreinal. Un golpe devastador vino asestado en 1539 con la muerte de la Emperatriz Isabel, que acentúo intensamente esa melancolía, estado anímico que algunos de sus contemporáneos señalaban como distintivo del emperador.

Vivió una vida itinerante, siempre de un sitio hacia otro, en constante conflicto bélico, no olvidemos la prolongada rivalidad con Francisco I o sus hostilidades con la curia romana, disfrutó poco del gran amor de su vida y, a pesar de ser el hombre más poderoso de su tiempo, 


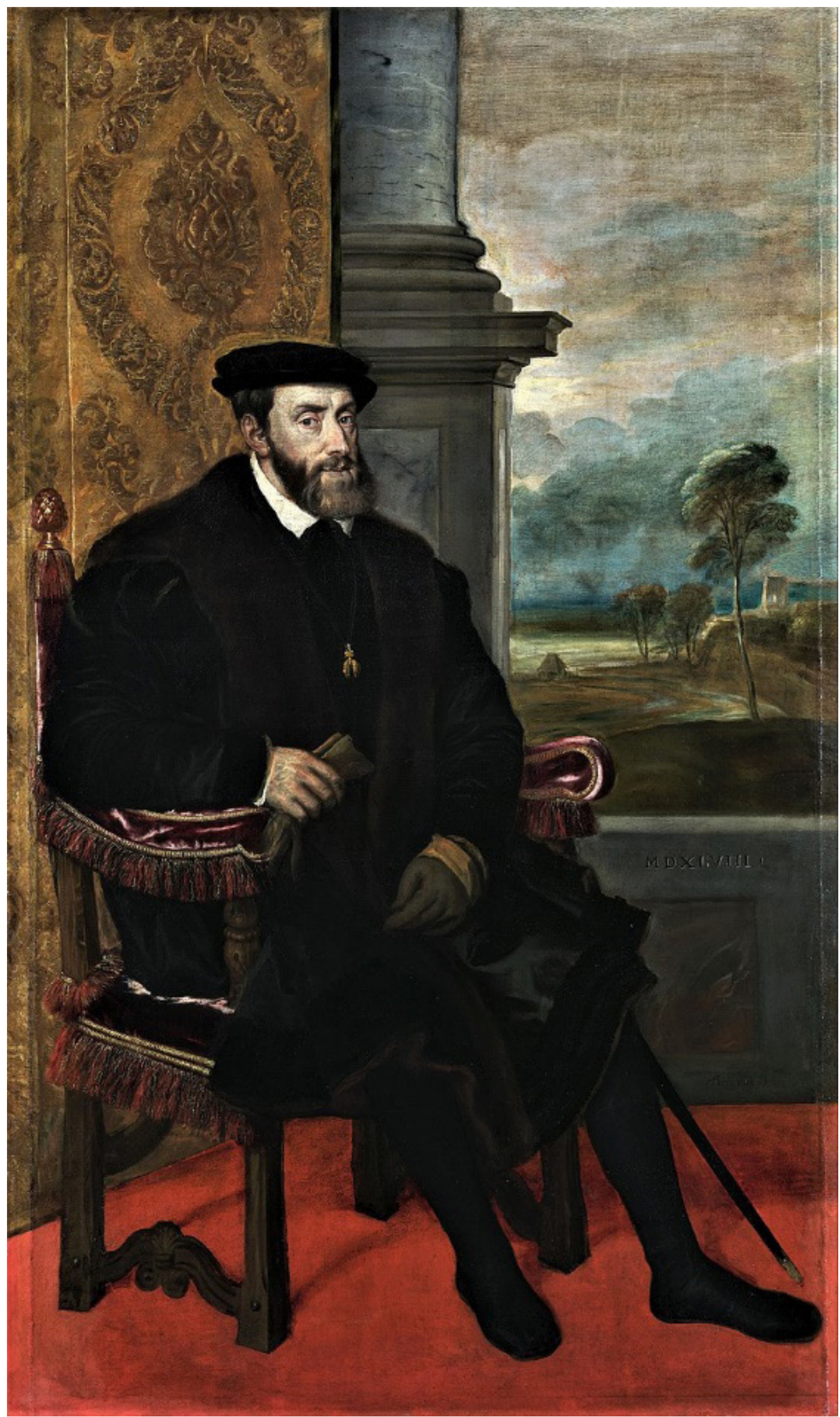

Figura 5. Tiziano. Carlos V sentado. 1548. Alte Pinakothek. 
se retiró voluntariamente a morir solo, alejado de toda riqueza, en un remoto monasterio extremeño. Llegados a este punto, resulta interesante referirnos de nuevo a los preceptos aristotélicos sobre la melancolía. En la sección XXX de Problemas, Aristóteles sugiere que el exceso de uno de los cuatro humores corporales, en este caso de bilis negra, podía producir diferentes efectos en las personas, enfermando gravemente o convirtiéndose en genios. Los grandes hombres, los "que han sobresalido en filosofía, política, poesía o arte" (Aristóteles, trad. en 2004:953 a), se encontraban siempre al borde del precipicio, entre la depresión enfermiza o la genialidad. Atrevido sería afirmar que el César cayó en esta melancolía profunda al final de sus días, pero el transcurso de su vida, el no éxito de sus objetivos vitales y la decisión de alejarse de todo, bien nos invita a pensarlo. Y más aún, si contemplamos su imagen afligida en las obras del que consideró su retratista por excelencia.

El colofón de la novela de Mujica Láinez es el retiro del emperador en Yuste, tema central de la obra Premio "Ciudad de Salamanca" de novela 2015 de José Antonio Ramírez Lozano. En El relojero de Yuste. Los últimos días de Carlos V, el extremeño, no solo da forma a una rigurosa novela histórica, sino que expresa, con un delicioso lirismo y un acertado uso simbólico del lenguaje, cuáles fueron los miedos, angustias y pesares que asolaron a Carlos $\mathrm{V}$ en sus últimos días. La novela discurre entre los recuerdos personales del César, en los que repasa las grandes gestas de su vida, rumiando sus fracasos y temiendo el veredicto divino. Veamos algunos pasajes, cuando habla con el fantasma de su amada Isabel: "Innsbruck y Metz emborronaron mi honra amada. He llegado a la vera de ese puente con las manos vacías, Isabel. No fui capaz de conquistar el imperio que Él mismo me demandaba y para el que me armó en Bolonia caballero" (Ramírez Lozano, 2015: 27). El verdadero hilo conductor de toda la obra es, al igual que en el cuento de Mujica Láinez, su batalla contra la muerte. Para ello se sirve de su relojero, Juanelo Turriano, con el que mantiene el siguiente diálogo:

Sí, como dices, puedes hacer concordar mis días con los astros esa tuya será la maquinaría más útil que conozco; más provechosa aún que todas las de guerra. Porque quiero confesarte que he determinado disputarle mis días a la Muerte en singular batalla y que tú seas mi maestre artillero. Ya sé que a ésa no se le combate con bombardas, sino arrebatándole la madeja del tiempo con que hila los minutos de mis horas (Ramírez Lozano, 2015:44).

A esto el relojero le contesta que "es batalla perdida de antemano", pero el César le replica:

[...]Sabido es, amigo Juanelo, que habremos de morir, pero el día y la hora está en nuestra mano retrasarlos. Y a esa dilación y tardanza llamo yo victoria. Sin duda, la guerra la daremos por perdida, más no así la batalla. La victoria no es suya sino de Dios, y así la dejaremos por burlada (Ramírez Lozano, 2015: 45).

Esta actitud combativa del emperador, es la que también observábamos en el inicio del cuento de Mujica Láinez, cuando el César se zambulle en la pintura de Brueghel. Además, hay otros elementos coincidentes entre ambas obras, nos referimos por ejemplo, al recurrir a la música para aliviar la tristeza que afecta a las criaturas que pueblan los cuadros del Prado. Mujica Láinez (1984) alude a ella en varias ocasiones, pero atendiendo a los protagonistas de este texto, citaremos el tercer capítulo cuando durante el desfile para elegir al pintor más elegante, es el turno de Tiziano, y dice así:

Confirmase la astucia del patriarca Tiziano por el hecho de que, no bien aparecen, con paso grave, encuadrando a la Emperatriz [...] suenan a la distancia los dos órganos que en sendas pinturas suyas, similares, tocan para otras tantas Venus y Cupidos, lo que alude un fondo musical tan sutil como los paisajes tizianescos, a la presencia de las augustas personas (42).

Muy sutilmente el escritor argentino manifiesta que los retratados por Tiziano, hacen gala no solo de su solemnidad, sino también de su tristeza, por lo que requieren del acompañamiento musical que alivie su pesadumbre. Por su parte, Juan Antonio Ramirez (2015), igualmente atribuye a la música ese poder curativo cuando, en un arrebato de dolor físico y emocional, el padre Regla (confesor del emperador) determina lo siguiente: 
[...] Piense que el dolor no es cosa vana, sino grandísimo patrimonio que no conviene malgastar a cuenta de la desesperanza. Es él quien prueba los mejores soldados. Muchos son los que siguen a Jesús a la mesa hasta partir el pan, pero pocos hasta beber el cáliz de su pasión (55).

Pero Carlos sufre más por su mal interior y replica: "El suyo padre Regla, es un consuelo venidero en el que el alma empeña su quebranto terrenal. Yo quiero mejor ahora un consuelo parejo de mi daño, porque así lo mitigue. La música, traedme siquiera una vihuela" (Ramirez, Lozano, 2015:55).

La novela de Juan Antonio Ramirez finaliza cuando el emperador acaba siendo derrotado. Tras seis días robados a la muerte, gracias al reloj de Juanelo, el César está convaleciente y el ingeniero es encerrado en el establo por los frailes del convento. Lo que impide que acuda a velar por el funcionamiento del reloj construido para Carlos V. Su encierro viene motivado por la desconfianza de los frailes que consideraban heréticos sus artilugios, hay que tener en cuenta que con Felipe II la represión inquisitorial será más acentuada. Atendamos a un fragmento de la novela, justo cuando Juanelo está preso de los frailes y uno de ellos sentencia: "Las horas que le quedan a su Majestad [...] son horas de Dios y las marcarán las campanas y no ese artilugio calvinista” (Ramírez Lozano, 2015:194).

Volviendo a la obra de Mujica Láinez (1984), él también da fin a su novela apuntando a la resignación última del emperador en Yuste, a través de este lienzo literario: "Él cabalgaba, meditabundo, con el ceño fruncido. Lo pasmaba no haber logrado vencer. [...]. Empezaba a comprender, desconcertado, lo que verificaría en el monasterio de Yuste, once años más tarde" (151-152).

Ya lo advirtió Brueghel en su pintura, ni el más poderoso ser escapa al final que a todos nos espera. Pese a esto, Carlos V sí que venció, metafóricamente hablando, a la Muerte, y es que su figura, su vida y sus obras se han perpetuado en la Historia. No solo a través de los múltiples cronistas, tanto contemporáneos a su vida, como posteriores, sino que a él mismo le preocupaba la imagen propia que quedaría grabada mediante la tinta. En su doble naturaleza, de hombre de armas sobre todo, pero también protector de las letras, se lanza a escribir sus memorias. En estas, se pueden distinguir dos partes: una primera que arranca desde 1515, y que nos habla de viajes, enlaces matrimoniales, entrevistas con personajes determinantes y otros aspectos biográficos, y una segunda que comprende los años de 1541 a 1548, y que ahonda en las empresas militares del emperador, es una especie de diario de campaña, así lo han calificado autores como Brandi o Fernández Alvárez (1973:470-471). El César quería alcanzar la gloria a través del reconocimiento de sus empresas militares, pues había recurrido a las armas por causas justas, siendo estas a juicio de Sepúlveda: la defensa de la religión, de la patria, del orden o de la dignidad. Y no solo eso, sino que en su opinión, la verdadera gloria, que no la fama popular, se logrará practicando la virtud, yendo esta ligada al cumplimiento del fin para el que cada individuo ha sido designado, de esta forma alcanzaría la gloria eterna (Espigares Pinilla, 1992:155 y 182). Juan Antonio Ramírez refleja muy bien el temor del César, a no haber cumplido su misión a los ojos de Dios, en la conversación que mantiene con su estimado Francisco de Borja:

¿Y mis pecados Francisco? ¿Mis pecados también? ¿Y mis derrotas? He llegado hasta aquí con las manos vacías para Dios, sin méritos que avalen mi propia salvación. Gasté la vida en fundar el Imperio de Cristo y no he conseguido otra cosa que dejar maltrecha su casa, desordenados sus reinos todos [...] (Ramírez Lozano, 2015:37).

Esta actitud mesiánica ya se manifestaba en los años 20, y así lo atestiguan las palabras pronunciadas durante la Dieta de Worms:

Estoy completamente decidido a dedicar mis reinos y señoríos, mis amigos, mi cuerpo, mi sangre, mi vida y mi alma porque sería gran vergüenza a mí y a vosotros, que sois la noble y muy nombrada nación de Alemania, y que somos por privilegio y preeminencia singular instituidos defensores y protectores de la Fe católica, que en nuestros tiempos no solamente heregia, mas ni suspición de ella, ni disminución de la Religión cristiana, por nuestra negligencia, en nosotros se sintiese, y que después de 
Nos quedase en los corazones de los hombres para nuestra perpetua deshonra y daño y de nuestros sucesores (Sandoval, 1955-1956, Libro noveno, 1521, X).

Sin embargo, el discurso simbólico de la imagen carolina fue cambiante a lo largo de los años, y ya en la década de los años 30, el sentido del deber caballeresco paso a un segundo plano, cediendo todo el protagonismo a los modelos clásicos italianizantes. En los años 40, tras el cese de los enfrentamientos con Francia y con la Italia pacificada, el foco de acción se traslada al problema luterano de Alemania, se inicia un discurso irenista que quiere mostrar al emperador como el aliado de los más desfavorecidos, capaz de encontrar una solución pacífica al conflicto de la división religiosa. En cierto modo, se retoma el modelo caballeresco de los años 20, pero ahora, volviendo a encontrarse con los círculos erasmistas, abogando por la paz (Gonzalo SánchezMolero, 2001). De ahí la versión tizianesca de la victoria en Mühlberg, en la que no aparecen los vencidos, ni su superioridad en la batalla, únicamente la figura a caballo del emperador se recorta sobre los campos del Elba. No advertimos la euforia del perseguido triunfo, pero sí la honorabilidad del que, considerándose elegido para un fin, siente haberlo cumplido. Fernando Checa insiste en que, en esta campaña, el tema del perdón es uno de los elementos retóricos que se utilizan en la construcción de la imagen cesárea y que entronca con la virtud heroica (1999:266).

De manera que, en el mes de junio de 1550, surcando las aguas del Rin, Carlos V toma la determinación de dejar constancia escrita de sus memorias, asesorado por su ayuda de cámara en aquel entonces, Guillermo van Male. Proyecto que quedó interrumpido en 1552, cuando es asediado en Innsbruck por Mauricio de Sajonia. Ante el temor de ser capturado y para evitar que las memorias cayesen en manos inapropiadas, las envía a Felipe II, quedando las mismas en territorio español. Cuando decide terminar sus días en Yuste, recoge las memorias para proseguir su redacción. Esto explicaría que algunos de los pocos libros que le acompañaron en su retiro fuesen, una edición francesa y otra española de su libro favorito, El caballero determinado de Olivier de la Marche, y Comentarios de Julio César, del que toma el estilo de escribir en tercera persona (Fernández Alvarez, 1973). Anhelaba encarnar al caballero determinando, que tanto admiraba, así como al emperador romano que se sumerge en el campo de batalla y después atestigua por escrito el transcurso de los hechos. El retrato de Tiziano en Mühlberg, protagonista del último cuento de Mújica Láinez, será el que mejor encarne esa dualidad, caballero cristiano (miles christi)-héroe clásico, que definió al propio Carlos V.

Igual que se encargó personalmente de establecer una imagen simbólica, a través del arte, quiso hacerlo con la palabra escrita mediante sus memorias. Esa consciencia del valor propagandístico de los distintos géneros artísticos, o de la alta difusión que podía lograr la imprenta, fue actitud heredada de su abuelo Maximiliano. Sin embargo, cuando Carlos se instaló en Yuste no retomó la actividad biográfica, que había quedado plasmada hasta 1548. Puede que debido a su delicada salud o, como magníficamente ha trazado Juan Antonio Ramirez en su novela, la intranquilidad de su conciencia, ante el peso de lo que él sentía como "sus fracasos" tuviese mucho que ver.

Para terminar, tras el fallecimiento del César, en 1558, se organizaron solemnes $\mathrm{y}$ fastuosas exequias fúnebres en algunas de las principales ciudades de su imperio como Bruselas, Valladolid o México. Fruto artístico de estas actividades fueron los túmulos arquitectónicos, cuyo programa iconográfico tuvo el fin último de mostrar, no el vencimiento de la Muerte, sino la supervivencia de la figura del emperador gracias a la Fama y a la Historia (Checa Cremades, 1999). Apreciamos como, aún con el transcurrir de los siglos, el emperador Carlos V sigue proyectando esa aura magnética que hoy lo convierte en tema central de tantos y tantos proyectos. El Arte incrementa esa atracción, siendo testigo visible de la Historia y hace posible esa perpetuidad. Mujica Láinez, ya supo verlo en Un novelista en el Museo del Prado, donde todos los representados han superado la barrera temporal a través de la única forma de eternidad posible, el Arte. Y puede que sea esa la razón de que Manucho gustase de llamarse mejor artista que intelectual, pues eso le emparentaba directamente con aquellos elegidos por Saturno, los melancólicos, a quien dedica su última obra y a la que nuestro eterno César, con su victoria/derrota, sirve como colofón. 


\section{REFERENCIAS BIBLIOGRÁFICAS}

- Agudelo, P.A. (2011). Los ojos de la palabra. La construcción del concepto de Ecfrasis de la retórica antigua a la crítica literaria. Lingüística y literatura,60, 75-92. Recuperado de: https://dialnet.unirioja.es/descarga/articulo/3943091.pdf

- Aristóteles. (2004) Problemas. Sánchez Millán, E (trad.). Madrid: Gredos.

- Blanco Fresnadillo, L. (2013). La poética de Manuel Mujica Lainez. Fábula e Iconografía. Málaga: Servicio de Publicaciones y Divulgación Científica de la Universidad de Málaga.

- Blanco Fresnadillo, L. (2018). Manuel Mujica Lainez. Un novelista en el Museo del Prado o el alegato de una poética. Transatlantic Studies Network: Revista de Estudios Internacionales,6, 71-82. Recuperado de: http://transatlanticstudiesnetwork.uma. es/?p=3451.

- - Checa Cremades, F. (1999). Carlos V y la imagen del poder en el Renacimiento. Madrid: El Viso.

- De Villena, L.A. (10 Septiembre, 2010). Mujica Láinez, cien años. El Mundo. Recuperado de: http://uisantoniodevillena.es/web/articulos/mujica-lainez-cien-anos/

- D’Ors, E. Tres horas en el Museo del Prado (1923/1993). Madrid: Anaya.

- Espigares Pinilla, A. (1992). La cuestión del honor y la gloria en el humanismo del siglo XVI a través del estudio del Gonsalus de Ginés de Sepúlveda y del De honore de Fox Morcillo (Memoria para optar al grado de Doctor). Recuperada de: https://eprints.ucm.es/id/eprint/3309/1/ T18021.pdf

- Fernández Álvarez, M. (1973). Corpus documental de Carlos V. Tomo IV (1954-1958). Salamanca: Ediciones Universidad de Salamanca. Recuperado de: https://eusal.es/index. php/eusal/catalog/view/978-84-600-6720-7/5588/6413-1

- García Añoveros, J.M. (2000). Carlos V y la abolición de la esclavitud de los indios. Causas, evolución y circunstancias. Revista de indias, 60 (218), 58-84. Recuperado de: http:// revistadeindias.revistas.csic.es/index.php/revistadeindias/article/download/581/648

- - Gónzalo Sánchez- Molero, J.L. (2001). El humanismo áulico carolino: discursos y evolución. En Martínez Millán, J., Bravo Lozano, J. y Labrador Arroyo, F. (Coords.). Carlos $V$ y la quiebra del humanismo politico en Europa (1530-1558): [Congreso internacional, Madrid 3-6 de julio de 2000], (pp. 125-152). Madrid: Sociedad Estatal para la Conmemoración de los Centenarios de Felipe II y Carlos V.

- Klibansky, R., Panofsky, E., Saxl, F. (1991/2004). Saturno y la melancolía. Estudios de historia de la filosofía de la naturaleza, la religión y el arte. Madrid: Alianza Editorial.

- Mancini, M. La elaboración de nuevos modelos en la retratista carolina: la relación privilegiada entre el Emperador y Tiziano (2000). En M.J. Redondo Cantera y M.A. Zalema (Coords.). Carlos V y las Artes. Promoción artística y familia imperial. Valladolid: Universidad de Valladolid, 221-235.

- Mujica Láinez, M (1984). Un novelista en el Museo del Prado. (2ª ed). Barcelona: Seix Barral.

- Pérez. J. (2000). La ideal imperial de Carlos V. En Castellano Castellano, J. y Sánchez Montes González, F. (Dir.). Carlos V, europeísmo y universalidad: [Congreso Internacional, Granada, mayo de 2000]. Madrid: Sociedad Estatal para la Conmemoración de los Centenarios de Felipe II y Carlos V, 239-250.

- Sandoval, P (1955-56). Historia de la vida y hechos del Emperador Carlos V. Seco Serrano, C. (Ed.). Historia de la vida y hechos del Emperador Carlos V. Recuperado de: http://www. cervantesvirtual.com/obra-visor/historia-de-la-vida-y-hechos-del-emperador-carlos-v--2/ html/ 